\title{
Entidades do Sistema S: Iniciativas e parcerias para o desenvolvimento socioeconômico dos municípios Brasileiros
}

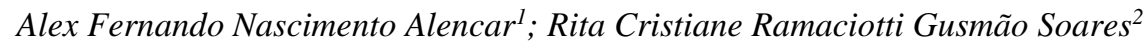

\begin{abstract}
Resumo: O presente artigo tem como principal objetivo de discutir e apresentar uma análise acerca da importância da educação profissional e do potencial de parcerias e iniciativas de fortalecimento das entidades integrantes do Sistema S, apresentando reflexões sobre a possibilidade de mudança educacional nos municípios Brasileiros, como ferramenta de estimular o desenvolvimento socioeconômico. Trataremos da história das entidades de sistema $\mathrm{S}$ e da necessidade de fortalecimento destas instituições como fundamentais ao desenvolvimento Brasileiro. Através de metodologia qualitativa, sendo constituída a partir de uma pesquisa e revisão bibliográfica que subsidiou a coleta de dados primários, a partir de livros, revistas, artigos e pesquisas em endereços na internet.
\end{abstract}

Palavras-Chave: Sistema S; Políticas Públicas; Educação Profissional; Desenvolvimento.

\section{Entities of System S: Initiatives and partnerships for the socioeconomic development of Brazilian municipalities}

\begin{abstract}
The main objective of this article is to discuss and present an analysis of the importance of professional education and the potential of partnerships and initiatives to strengthen the entities of the $\mathrm{S}$ system, presenting reflections on the Possibility of educational change in Brazilian municipalities, as a tool to stimulate socioeconomic development. We will deal with the history of the S system entities and the need to strengthen these institutions as fundamental to Brazilian development. Through the methodology of qualitative class, being constituted from a bibliographic research and review that supported the collection of primary data, from books, magazines, articles and researches on Internet addresses.
\end{abstract}

Keywords: System S; Public policies; Vocational education; Development.

\section{Introdução}

Criado durante o governo do então presidente Getúlio Vargas, o Sistema S é composto por diversas instituições que juntas representam um conjunto de organizações e entidades destinadas ao apoio de desenvolvimento de categorias profissionais. De uma forma geral, essas entidades apoiam diversas áreas econômicas a exemplo da indústria e do comércio.

\footnotetext{
${ }^{1}$ Pós-Graduando em Gestão Pública Municipal (UNIVASF). alexfnalencar@hotmail.com;

${ }^{2}$ Rita Cristiane Ramaciotti Gusmão Soares. Mestre em Administração Pública (UNIVASF).

Contato: cristianegusmao@gmail.com.
} 
O sistema é financiado além de recursos próprios advindos da prestação de serviços e da oferta de capacitação ao público em geral, é mantido também mediante a contribuição compulsória das empresas, com alíquotas variadas, a depender do tipo de negócio e da tributação do empreendimento. O sistema surgiu como instrumento de defesa dos interesses de diversos ramos da economia e visa apoiar a administração pública em atividades educacionais e sociais, mediante a oferta de capacitação, qualidade de vida e formação da mão de obra produtiva Brasileira.

Uma das principais entidades do Sistema S é o SENAI - Serviço Nacional de Aprendizagem Industrial, entidade voltada a formação de profissionais capacitados para atuarem no fortalecimento e aumento da competitividade da indústria nacional.

Traremos neste artigo opiniões de outros autores que possam nos ajudar na conscientização e reflexão da importância do sistema $\mathrm{S}$ para o crescimento do país e o fortalecimento das instituições empresariais, como parceiros como forma de estimular a retomada da economia e promover um país mais justo e igualitário. $\mathrm{O}$ objetivo do sistema não é apenas ter mais unidades escolares no país, trata-se de um compromisso das organizações privadas aliado a administração pública afim de promover educação, saúde e qualidade de vida por meio dos serviços que oferecem, promovendo qualificação profissional e participação cidadã nas comunidades em que atuam.

\section{Histórico da Educação Profissional}

A história da educação profissional está vinculada aos primórdios da humanidade, quando os humanos, segundo Manfredi (2002), transferiam seus saberes profissionais por meio de uma educação baseada na observação, na prática e na repetição, pelas quais repassavam conhecimentos e técnicas de fabricação de utensílios, aprimoramento de ferramentas, instrumentos de caça, defesa e demais artefatos que lhes servissem e facilitassem o cotidiano.

No Brasil embora tradicionalmente o ofício dos pais seja repassado aos filhos, no que implica na transmissão de negócios no seio familiar, historicamente apenas no início do século XX ocorreram mudanças nas políticas de avanço da educação profissional. Essas

103 Id on Line Rev. Mult. Psic. V.13, N. 45 SUPLEMENTO 1, p. 102-109, 2019 - ISSN 1981-1179 Edição eletrônica em http://idonline.emnuvens.com.br/id 
políticas estão totalmente vinculadas aos avanços industriais Brasileiros e configuram essa educação como parceria forte no desenvolvimento socioeconômico, seja ele local ou nacional.

\section{Educação Profissional no Brasil}

1909 - O Decreto-Lei n ${ }^{\circ}$ 7.5662, de 23 de setembro de 1909, sancionado pelo então Presidente da República Nilo Peçanha, instituiu oficialmente a educação profissional brasileira que, vista como instrumento de capacitação ou adestramento para atender ao crescente desenvolvimento industrial e ao ciclo de urbanização, tinha caráter assistencialista em relação à massa trabalhadora. Ocorreu a criação de 19 Escolas de Aprendizes Artífices, difundidas com o intuito de preparar gerações vindouras para a continuidade dos ofícios, suprindo, assim, o mercado produtivo, dominado pela burguesia emergente, formando profissionais advindos das camadas pobres da população. $\mathrm{O}$ ensino profissional foi delegado ao Ministério de Indústria e Comércio.

1910 - Foram ofertados cursos de tornearia, mecânica e eletricidade, além das oficinas de carpintaria e artes decorativas ministradas nas 19 Escolas de Aprendizes Artífices.

1930 - Ocorreu a instalação de escolas superiores para formação de recursos humanos necessários ao processo produtivo (início da Industrialização do Brasil). A partir da década de 1930, o ensino profissional se expandiu no Brasil, incluindo, em seu público-alvo, ricos e pobres.

1937 - A Constituição de 1937 fez menção às escolas vocacionais e pré-vocacionais como dever do Estado, a quem competia, com a colaboração das indústrias e dos sindicatos econômicos, criar, na esfera de sua especialidade, escolas de aprendizes, destinadas aos filhos de seus operários e associados.

1940 - Amplitude de atendimento: criação das instituições responsáveis pela formação de mão-de-obra para os dois principais pilares da economia: a Indústria e o Comércio. Surgimento do chamado Sistema S4.

1942 - Criação do SENAI (S pioneiro). Criação da lei Orgânica da Educação Nacional do Ensino Secundário.

1943 - Criação da Lei Orgânica da Educação Nacional do Ensino Comercial.

104 Id on Line Rev. Mult. Psic. V.13, N. 45 SUPLEMENTO 1, p. 102-109, 2019 - ISSN 1981-1179 Edição eletrônica em http://idonline.emnuvens.com.br/id 
1946 - Criação do Serviço Nacional de Aprendizagem Comercial (SENAC), do Serviço Social do Comércio (SESC) e Serviço Social da Indústria (SESI). Criação da Lei Orgânica da Educação Nacional do Ensino Primário, Normal e Agrícola.

1990 - Criação do Serviço Nacional de Aprendizagem Rural (SENAR), do Serviço Nacional do Transporte (SENAT), do Serviço Nacional de Apoio ao Cooperativismo (SESCOOP) e do Serviço Brasileiro de Apoio à Pequena e Média Empresa (SEBRAE).

*Resumo de Lidiane Soares Wittaczik.

\section{Surgimento das Entidades do Sistema S}

Como visto no resumo acima, é nesse cenário de avanço da educação profissional que o país começa a galgar espaço entre grandes países industriais e começa a exportar diversos produtos, mostrando protagonismo no cenário internacional. Desde o surgimento das entidades do sistema $S$ o país avançou muito em termos econômicos e não podemos negar a contribuição dessas instituições para o progresso nacional.

Atuando em diferentes ramos da economia, a exemplo da indústria e do comércio, a entidades do sistema, capacitam mão de obra em todos os estados da federação, sendo hoje o SENAI, entidade do sistema S, a maior instituição de ensino da América Latina.

O surgimento dessas entidades, ainda na década de 1940, durante o mandato de Getúlio Vargas, além de congregar os anseios dos empresários em garantir mão de obra qualificada, surgiu em paralelo a outras ações de fortalecimento da classe trabalhadora, a exemplo da Consolidação das Leis Trabalhistas (CLT).

Com um regime de tributação diferenciada e imunidade em diversos casos, as organizações do Sistema S são chamadas de paraestatais, sendo instituições privadas, mas desempenham serviços de amplo interesse do estado, a exemplo dos serviços de formação educacional e qualidade de vida. São consideradas como organizações do terceiro setor e prestam contas a administração pública por meio dos órgãos fiscalizadores. No total, nove instituições, previstas na Constituição Federal, pertencem ao Sistema S. Cada uma delas tem uma área de atuação, como a indústria, o comércio, o agronegócio, o suporte as pequenas empresas e o cooperativismo. 


\section{Oportunidades de Parcerias}

Nos últimos anos, muito tem se falado em reduzir ou até mesmo acabar com o repasse das contribuições patronais para entidades do sistema S. Ainda em dezembro de 2018, antes que o então Presidente eleito, Jair Bolsonaro assumisse o posto máximo da República, o escolhido como ministro da Economia, Paulo Guedes, disse que pretendia "meter a faca no Sistema S“, deixando todas as confederações em atuação, desestabilizadas em relação a suas ações futuras. Embora o assunto esteja em alta no momento, o assunto já faz parte dos debates do congresso nacional a algum tempo, a exemplo do ano de 2016, quando o então ministro da fazenda Joaquim Levy, propôs reter até 30\% do valor repassado ao Sistema S. A verdade é de que o governo está a anos de olho no valores repassados ao sistema, que conforme a Controladoria Geral da União (CGU) nos anos de 2012, 2013 e 2014 as entidades tiveram receita anual de cerca de $\mathrm{R} \$ 30$ bilhões. É importante lembrar que desse montante de receitas, uma parte retorna ao segmento econômico na forma de ações educacionais e qualidade de vida aos trabalhadores, seja por meio de ações gratuitas ou ações subsidiadas.

É diante dessa disponibilidade, que devemos tratar acerca da possibilidade de parcerias e iniciativas que podem estimular a economia Brasileira nos municípios, promovendo educação de qualidade e diversas ações de saúde a diversas pessoas nos mais variados cantos do país. Com as contas controladas e com a grande maioria de suas ações bem fixadas e apoiadas pela grande maioria dos Brasileiros, as entidades do sistema $\mathrm{S}$, podem ter a oportunidade de investir em tecnologia, inovação e na abertura de novos mercados. Na realidade algumas dessas instituições já fazem isso, a exemplo do SENAI que por meio dos seus institutos de tecnologia espalhados pelos país, congregam pesquisadores em promover estudos nas áreas tecnológicas de forma a aumentar a competitividade da indústria nacional.

No entanto é chegada de hora de expansão para outras regiões, principalmente na interiorização dessas tecnologias. Ao invés de partir para o corte nos recursos, defendido pelo governo, é necessário fortalecer as instituições e utilizar essa tecnologia em ações amplas de cunho nacional para prover a educação profissional e tecnológica, bem como as ações de promoção da saúde e qualidade de vida. Um exemplo da necessidade dessa atuação é o semiárido Nordestino que padece com os longos períodos de estiagem mas continua a produzir riquezas para o país. O direcionamento de ações especificas a essas áreas, de forma a

106 Id on Line Rev. Mult. Psic. V.13, N. 45 SUPLEMENTO 1, p. 102-109, 2019 - ISSN 1981-1179 Edição eletrônica em http://idonline.emnuvens.com.br/id 
promover a ampla oferta de educação profissional é o primeiro passo para o desenvolvimento. É claro que o desenvolvimento econômico envolve outros fatores, mas a formação de mão de obra é o primeiro passo para esse avanço.

Podemos citar como exemplo a região do sertão de Pernambuco, é a maior região natural do Estado, uma vez que ocupa $70 \%$ do território pernambucano e possui apenas duas unidades do SENAI, localizadas em Araripina e Petrolina. Embora sejam instituições de destaque no Estado, pelas suas expertises reconhecidas em Tecnologia do Gesso e Tecnologia em Alimentos, respectivamente, atuam em diferentes áreas e fazem total diferença na formação educacional dos trabalhadores da indústria local. Cada uma dessas unidades atua em seus respectivos municípios e embora trabalhem principalmente voltadas ao desenvolvimento do agronegócio e na extração de gipsita, além de promoverem oferta de cursos e capacitações, ainda dispõe de laboratórios modernos e atuam com consultorias para desenvolver a atividade industrial. Essas ações podem ser expandidas e atenderem mais municípios, fortalecendo seu eixo de negócio de atuação.

Ao invés da promoção de cortes é necessário avaliar as possibilidades de desenvolvimento que as instituições do sistema $\mathrm{S}$ podem fornecer em cada área de atuação. Essas instituições já fizeram muito pelo país e podem continuar contribuindo com o crescimento, principalmente com ações especificas de desenvolvimento. O objetivo desse trabalho é levar o leitor a reflexão e que seja o primeiro passo para tantas ações que podem ser desenvolvidas, a exemplo dos municípios de menor porte, em ações para públicos específicos ou ainda em inciativas de levar tecnologia para as empresas menores. O necessário agora é continuar fortalecendo o sistema e discutindo a ampliação ou realização de novas ações, que possam promover a educação profissional e consequentemente o desenvolvimento econômico.

\section{Metodologia}

Essa pesquisa tem classe qualitativa, e através de pesquisa continua por meio de uma revisão bibliográfica foi feita a coleta a partir de publicações acadêmicas, livros, revistas, sites e outros tipos. Esse levantamento é primeiro trabalho acerca do potencial do sistema $\mathrm{S}$ no desenvolvimento econômico do país, com o objetivo de levar a reflexão acerca dos avanços

107 Id on Line Rev. Mult. Psic. V.13, N. 45 SUPLEMENTO 1, p. 102-109, 2019 - ISSN 1981-1179 Edição eletrônica em http://idonline.emnuvens.com.br/id 
obtidos pelo sistema. Essa abordagem qualitativa é importante para que o pesquisador possa analisar e interpretar as informações, permitindo novas descobertas de aprendizagem.

\section{Análise Bibliográfica}

As pesquisas acadêmicas têm mostrado o resultado das ações das entidades do sistema $\mathrm{S}$, como extremamente importantes para o país. Conforme o trabalho de Marta $\mathrm{M}$. Assumpção Rodrigues, "Muitos países da América Latina implementaram sistemas de Educação e Formação Profissional inspirados no formato brasileiro. O desenho do SENAI influenciou, por exemplo, a criação do Instituto Nacional de Aprendizaje (INA) na Costa Rica, o Servicio Nacional de Aprendizaje (SENA) colombiano e o Instituto Nacional de Cooperación Educativa (INCE) da Venezuela, entre outros. Mais recentemente, o SENAI ajudou a implementar políticas de formação profissional em países africanos como Cabo Verde (Castro 2003), Angola e Guiné-Bissau (FIESP 2012). Em 2012, o modelo do SENAI (São Paulo) passou a ser exportado para a Nigéria”.

Diante disto, se somos referência e exemplo em investimento em educação profissional é necessário expandir essas ações em mais municípios e aproveitar as oportunidades que o Sistema pode proporcionar no tocante a formação profissional.

\section{Considerações Finais}

Após a realização da pesquisa bibliográfica, a partir de análise documental, pudemos atestar a importâncias das entidades do sistema S, desde a sua origem na década de 1940 até os dias atuais. Nunca antes tivemos tanta necessidade de resgatar milhões de pessoas da falta de capacitação e promover a inserção no mercado de trabalho. Embora as instituições do sistema S, tenham surgido do anseio patronal de mão de obra qualificada, é fundamental reconhecer os avanços a economia como um todo. Precisamos defender e fortalecer essas instituições, promovendo estudos de análises e parcerias de desenvolvimento. Existem diversas oportunidades e essas entidades tem muito a contribuir com esse desenvolvimento que o país precisa.

108 Id on Line Rev. Mult. Psic. V.13, N. 45 SUPLEMENTO 1, p. 102-109, 2019 - ISSN 1981-1179 Edição eletrônica em http://idonline.emnuvens.com.br/id 


\section{Referências}

http://nupps.usp.br/downloads/relatorio2013/Anexo_05_IPEA\%20-\%20versao\%20final-5.pdf - Acesso em 15/05/2019.

http://www.estudosdotrabalho.org/8RevistaRET5.pdf - Acesso em 15/05/2019

https://epoca.globo.com/guilherme-amado/sistema-passa-se-submeter-mais-lei-de-acessoinformacao-23645000 - Acesso em 09-05-2019

http://blog.seguridade.com.br/sistema-s-entenda-o-que-e-e-quais-sao-as-areas-presentes/ Acesso em 09/05/2019

file://C:/Users/alex.alencar/AppData/Local/Packages/Microsoft.MicrosoftEdge_8wekyb3d8b bwe/TempState/Downloads/26-Texto\%20do\%20artigo-106-1-10-20080412\%20(1).pdf Acesso em 09/05/2019

file:///C:/Users/alex.alencar/AppData/Local/Packages/Microsoft.MicrosoftEdge_8wekyb3d8b bwe/TempState/Downloads/8639814-Texto\%20do\%20artigo-10372-1-10$20150902 \% 20(1) . p d f-$ Acesso em 15/05/2019.

\section{Como citar este artigo (Formato ABNT):}

ALENCAR, Alex Fernando Nascimento; SOARES, Rita Cristiane Ramaciotti Gusmão. Entidades do Sistema S: Iniciativas e parcerias para o desenvolvimento socioeconômico dos municípios Brasileiros. Id on Line Rev.Mult. Psic., 2019, vol.13, n.45 SUPLEMENTO 1, p. 102-109. ISSN: 1981-1179.

Recebido: $15 / 05 / 2019$

Aceito 17/05/2019 